\title{
Umbilical Cord Finding
}

National Cancer Institute

\section{Source}

National Cancer Institute. Umbilical Cord Finding. NCI Thesaurus. Code C117360.

Clinical and laboratory findings about the umbilical cord. 